\title{
MicroRNA, sex determination and floral meristem determinacy in maize Jo Ann Banks
}

Address: Department of Botany and Plant Pathology, Purdue University, West Lafayette, Indiana 47907, USA. Email: banksj@purdue.edu

\author{
Published: 30 January 2008 \\ Genome Biology 2008, 9:204 (doi:10.1 I86/gb-2008-9-I-204)
}

The electronic version of this article is the complete one and can be found online at http://genomebiology.com/2008/9/1/204

(c) 2008 BioMed Central Ltd

\begin{abstract}
Sex determination in the flowers of maize involves the abortion of stamen or pistil development. Recent work investigating genes that control this process reveals that a microRNA is involved in both the sex determination of the male inflorescence and its growth pattern.
\end{abstract}

The decision to develop as a male or female is fundamental to most life forms. In animals the genetic and environmental signals that influence this decision are diverse and the subject of intense study, yet this question has received relatively little attention in plants. Why the difference? While unisexuality is common in animals, it is not so common in flowering plants. The model plant Arabidopsis thaliana, for example, has perfect (bisexual) flowers with pollen-producing stamens and ovuleproducing pistils wrapped in whorls of petals and sepals. While we have a clear understanding of how the identity of floral organs is controlled in Arabidopsis, this plant is of limited value for understanding how plant species have attained unisexuality. For the most part, flowering plants with bisexual flowers have collectively evolved a multitude of additional and interesting mechanisms to avoid selffertilization, which most animal species avoid by making sure that each individual is unisexual and populations have equal proportions of males and females.

Of those flowering plant species that do produce unisexual flowers, some are dioecious, having strictly male or female flowers and unisexual individuals, whereas others are monoecious and produce both unisexual male and female flowers but on the same plant. Maize (Zea mays) is a monoecious plant that produces imperfect (unisexual) male flowers, or florets, in the tassel and imperfect female florets in the ear. In maize, imperfect florets arise by the arrest of stamen development in female flowers and by the abortion of pistil primordials in the male, suggesting that sex determination is not a problem of floral-organ identity, but rather a matter of what regulates the arrest of stamen or pistil development in the ear and tassel florets, respectively. In maize, the application of the plant hormone gibberellin (GA) to tassels feminizes the tassel, whereas depletion of endogenous GA masculinizes ear florets [1], indicating that stamen and pistil development are under hormonal control. Given the rich history of maize genetics and the agronomic importance of its seeds, maize is an excellent and important system for understanding how unisexuality can evolve in flowering plants.

Mutations that feminize tassel florets can be identified easily by the presence of seeds and fuzzy silks (female stigmas) in the male tassel (Figure 1a). Six such tasselseed mutants were identified more than 50 years ago [2] and two of them, $t s 4$ (a recessive mutation) and Ts6 (a dominant mutation), have recently been cloned and characterized by Chuck et al. [3]. What is so significant about this recent study is that it reveals how sex determination (pistil abortion in this case) is regulated, and how this process is tied to a mechanism that regulates when a meristem switches from an indeterminate to a determinate, or terminal, state. Understanding this connection first requires a basic understanding of the structure and development of the tassel.

The architecture of the maize tassel is fairly complex (Figure 1a), even though the hundreds of individual tassel florets are extremely reduced in size and simple in structure, as illustrated in Figure 1b. Each male floret consists of two bracts (the lemma and palea), two minute scales called lodicules, and three stamens. Florets are organized into units, called spikelets, with each spikelet enclosed by two bracts called glumes. In maize, each male spikelet contains 

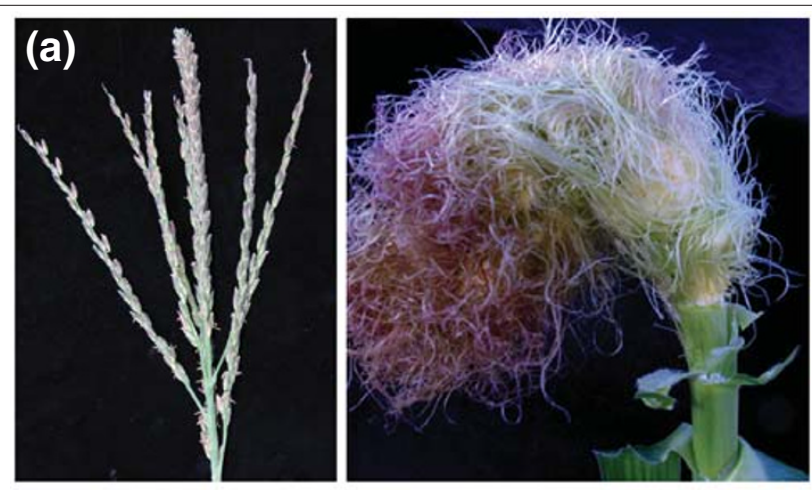

(b)

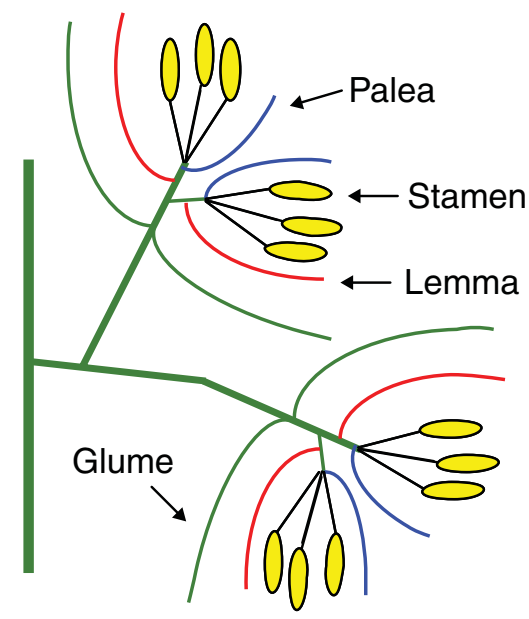

Figure I

Organization of the male inflorescence and flowers in maize.

(a) Inflorescences (tassels) of wild-type (left) and ts 4 (right) plants. The normal male tassel is composed of branches (spikes), each of which is made up of spikelets containing two florets each. The threads in the ts 4 mutant are female stigmas. (b) A schematic illustration of two male spikelets, each of which is composed of two florets and enclosed by two bracts called glumes. Each floret consists of three stamens enclosed by two bracts, the lemma and the palea (the lodicules are not shown here). Photographs and illustration courtesy of George Chuck.

two florets, while those in the ear contain one. The spikelets are collectively organized into units called spikes, with many spikes collectively making up the tassel. The organization of spike, spikelets and florets is engineered by the inflorescence apical meristem, which contains the population of stem cells that deliver new daughter cells to the growing plant. As the spike inflorescence develops, the inflorescence meristem continuously forms new branch derivatives that initiate spikelet pair meristems; after branching, each spikelet pair meristem undergoes a transition to produce two spikelet meristems; each spikelet meristem then undergoes a transition to produce two floret meristems that initiate the organs of the floret. Eventually, all meristems terminate, the florets mature, open and shed their pollen.
The tassels of mutant ts 4 plants differ from wild type in several ways (see Figure 1a): they have feminized florets, show increased spikelet branching and typically produce more than two florets per spikelet. The increase in branching and floret number reflects an inability of the meristems to switch from an indeterminate to a determinate state as the tassel develops. Thus, in addition to promoting male development, the wild-type ts 4 gene functions to impose determinacy on the spikelet and spikelet pair meristems.

To understand how these tasselseed genes control sex determination in the male floret, Chuck and colleagues [3] cloned the ts4 gene and discovered that it is a member of the miR172 family of microRNAs (miRNAs) that is known to regulate the APETALA2 (AP2) family of transcription factors $[4,5]$. As it turns out, the same authors had previously shown that the maize indeterminate spikelet1 (ids1) gene encodes an AP2-like gene [6]. Like ts4 tassels, ids1 tassels produce additional florets; however, ids1 florets in the tassel are not feminized like the $t s 4$ florets.

To see whether ids1 is a target of ts4, Chuck et al. [3] examined the phenotypes of the ts 4 ids1 double-mutant plants and observed that ids1 suppressed the sex determination defect of $t s 4$, providing support for the supposition that ids1 is a target of ts4. In another series of interesting experiments, the authors also discovered that Ts6 and ids1 are variants of the same gene, even though the two mutants have different phenotypes (the tassel florets of Ts6 plants are often feminized [7] whereas ids1 florets are not). Comparing the sequences of Ts6 and ids1 revealed that two independent Ts6 mutations alter the 5' end of the miR172-binding site in this AP2-like gene, leading to a dominant phenotype, whereas two independent ids1 mutants are caused by insertions of the Mutator transposon into different introns of the same gene, leading to a loss-of-function phenotype. As $i d s 1$ transcripts are present in both wild-type and ts4 mutant plants, ts 4 is likely to regulate the synthesis of the IDS1 protein. Translational repression of the AP2 protein by miR172 has also been observed in Arabidopsis [5]. Immunolocalization in wild-type and mutant ts 4 tassels revealed that IDS1 is ectopically expressed in the pistils of mutant ts4 florets and is elevated during floral-meristem initiation. These observations led to a simple model of the regulation of sex determination by IDS 1 in the tassel florets of maize, illustrated in Figure 2.

How ids1 affects branching and meristem transitions is not clear, although some clues are provided by the characterization of ap2 mutations in Arabidopsis. In Arabidopsis, ectopic expression of a mutant form of ap2 altered in its miRNA172-binding site leads to several floral defects, including the loss of floral determinacy [5]. This phenotype mimics the agamous (ag) phenotype, consistent with the function of $A G$ as necessary for carpel initiation [8]. Chuck et al. [3] propose that a similar relationship between ids1 


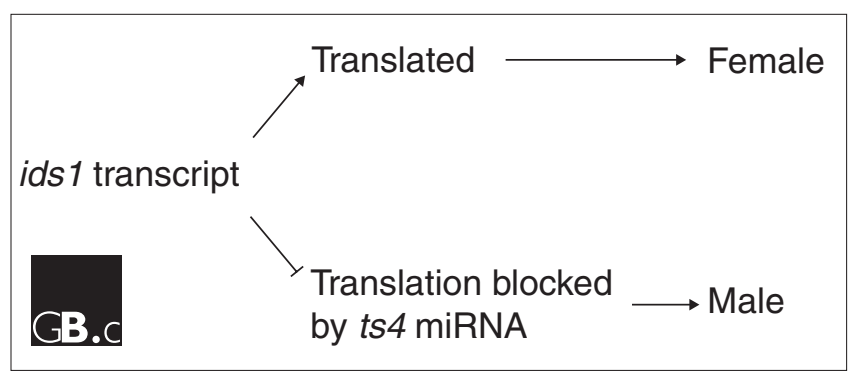

Figure 2

The sex of the tassel florets depends on the translation of the IDSI transcript. In normal male florets, IDSI mRNA is not translated because of the presence of the ts 4 miRNA (miRNAI72). If an IDSI protein is produced, either as a result of a loss-of-function mutation in the ts 4 gene or a mutation in the miRNA-binding site in ids I (which has occurred in the mutant Ts6), the floret is female.

and an $A G$-like gene could occur in maize. By reducing $A G$ expression in the floret, the prolonged expression of ids1 would prevent the differentiation of stem cells in the meristem, thus allowing the spikelet meristem to form additional floret meristems. This and other hypotheses remain to be tested.

From an evolutionary perspective, it will be interesting to see if the mechanism of sex determination in maize that is defined by ts 4 and ids 1 is common to other monoecious or dioecious species of plants, including the homosporous ferns, which determine their sexual phenotype during the gametophytic phase of growth and where meristem development and sex determination go hand-in-hand [9]. Given that monoecy has evolved multiple times in different angiosperm lineages, and dioecy often follows [10], the study of Chuck et al. [3] provides new tools to understand how widespread this mechanism of sex determination is.

\section{References}

I. Nickerson $\mathrm{NH}$ : Sustained treatment with gibberellin acid of five different kinds of maize. Ann Mo Bot Gard 1959, 46:19-37.

2. Veit B, Schmidt RJ, Hake S, Yanofsky MF: Maize floral development: new genes and old mutants. Plant Cell 1993, 5:I205-I2I5.

3. Chuck G, Meeley R, Irish E, Sakai H, Hake S: The maize tasselseed4 microRNA controls sex determination and meristem cell fate by targeting Tasselseed6/indeterminate spikeletl. Nat Genet 2007, 39:1517-1521.

4. Aukerman MJ, Sakai $\mathrm{H}$ : Regulation of flowering time and floral organ identity by a microRNA and its APETALA2-like target genes. Plant Cell 2003, 15:2730-274I.

5. Chen X: A microRNA as a translational repressor of APETALA2 in Arabidopsis flower development. Science 2004, 303:2022-2025.

6. Chuck G, Meeley RB, Hake S: The control of maize spikelet meristem fate by the APETALA2-like gene indeterminate spikeletl. Genes Dev 1998, I2: I |45- I I54.

7. Irish EE: Experimental analysis of tassel development in the maize mutant tassel seed 6. Plant Physiol 1997, I 14:817-825.

8. Lohmann JU, Weigel D: Building beauty: the genetic control of floral patterning. Dev Cell 2002, 2: I35-142.

9. Tanurdzic M, Banks JA: Sex-determining mechanisms in land plants. Plant Cell 2004, I6 Suppl:S6I-S7I.

10. Geber MA, Dawson TE, Delph LF: Gender and Sexual Dimorphism in Flowering Plants. Berlin: Springer; 1999. 